\title{
The EU $40 \%$ greenhouse gas emission reduction target by 2030 in perspective
}

\author{
A. F. Hof ${ }^{1,2} \cdot$ M. G. J. den Elzen ${ }^{1}$ A. Mendoza Beltran ${ }^{3}$
}

Accepted: 15 March 2016/Published online: 25 March 2016

(C) Springer Science+Business Media Dordrecht 2016

\begin{abstract}
We assess the fairness and ambition level of the EU's Intended Nationally Determined Contribution (INDC) of reducing domestic greenhouse gas emissions by at least $40 \%$ relative to 1990 . For this, we calculate which reduction targets for other major emitting economies are comparable to the EU target, given widely diverging effort-sharing approaches. We introduce a novel approach in which the EU target is taken as starting point for allocating emission reductions to other regions. Under this approach, the global emission level is an outcome of the analysis, contrary to standard effort-sharing approaches in which the global climate goal is specified. We find that the INDC of the EU, if other regions take on comparable targets based on a differentiated convergence per-capita approach, could be sufficient for a global $2{ }^{\circ} \mathrm{C}$ pathway. However, if emissions are allocated according to a historical responsibility approach, the global emission level in 2030 is much higher than the level of $2{ }^{\circ} \mathrm{C}$ pathways. Furthermore, we conclude that India, Mexico, and Brazil have more ambitious INDCs than the EU according to both a differentiated convergence per-capita approach and a historical responsibility approach.
\end{abstract}

Keywords Climate change $\cdot$ INDCs $\cdot$ Burden sharing $\cdot$ Effort sharing $\cdot$ Mitigation

Electronic supplementary material The online version of this article (doi:10.1007/s10784-016-9317-x) contains supplementary material, which is available to authorized users.

A. F. Hof

Andries.hof@pbl.nl

1 PBL Netherlands Environmental Assessment Agency, PO Box 303, 3720 AH Bilthoven, The Netherlands

2 Copernicus Institute of Sustainable Development, Utrecht University, Utrecht, The Netherlands

3 CML Industrial Ecology, Leiden University, PO Box 9518, 2300 RA Leiden, The Netherlands 


\section{Introduction}

Many countries have put forward greenhouse gas (GHG) emission reduction pledges for 2020 in the Cancún Agreements under the United Nations Framework Convention on Climate Change (UNFCCC 2010, 2012). Several studies have analyzed the effect of these pledges on global emissions and the chance of achieving the international agreed goal of keeping global temperature increase well below $2{ }^{\circ} \mathrm{C}$ by the end of the century (Rogelj et al. 2010; van Vliet et al. 2012; den Elzen et al. 2013a; Hof et al. 2013; UNEP 2014) and on abatement costs (den Elzen et al. 2011; Wada et al. 2012; Dellink et al. 2011; Peterson et al. 2011). However, emission reductions beyond 2020 are more important for achieving the international agreed climate goal of $2{ }^{\circ} \mathrm{C}$ (Tavoni et al. 2015; Riahi et al. 2015). According to the latest UNEP emission gap report (UNEP 2015) the median emission level needed for a likely (more than $66 \%$ ) chance of keeping temperature increase to below $2{ }^{\circ} \mathrm{C}$ is $42 \mathrm{GtCO}_{2}$ eq by 2030 , with a range of $31-44 \mathrm{GtCO}_{2}$ eq. At the same time, businessas-usual emissions are projected to increase during this period.

In 2011, at the UN climate summit in Durban, countries agreed to negotiate a new international climate agreement by 2015 , applicable to all countries and to be implemented from 2020. One of the key elements in the new agreement is the long-term reduction targets beyond 2020, as part of the so-called Intended Nationally Determined Contributions (INDCs). At the UN climate summit in Lima in 2014, it was agreed that countries should submit INDCs well before the Paris climate summit in December 2015. By October 29, 2015, 129 INDCs had been submitted to the UNFCCC secretariat, covering 156 countries (as the EU28 submitted one INDC). ${ }^{1}$ Many of these INDCs include some text about the fairness and ambition level, which shows that questions related to fairness and ambition are high on the political agenda. Furthermore, in the Paris Agreement (UNFCCC 2015), adopted in December 2015, countries agreed to submit new or updated national climate plans by 2020 (known as nationally determined contributions). Every five years after that, countries agreed to submit new contributions, which have to go beyond previous efforts depending on the collective progress toward achieving the global long-term temperature goal.

In this context, it is important to assess the fairness and ambition level of emission reduction targets of different countries. This can be done according to different effortsharing approaches. Such effort-sharing approaches are guided by certain equity principles, and based on the UNFCCC principle of common but differentiated responsibilities and respective capabilities (CBDR-RC, United Nations 1992). As the EU claims to be at the forefront of international efforts (European Commission 2014), the main aim of this paper is to assess the fairness and ambition level of the EU's INDC. In order to assess this, we address the following research questions:

1. Which targets for other countries or regions are comparable to the EU target of a $40 \%$ reduction in domestic GHG emissions by 2030 relative to 1990, given different effortsharing approaches?

2. Is the global emission level resulting from implementation of the INDC of the EU and comparable reductions from other countries consistent with $2{ }^{\circ} \mathrm{C}$ GHG emission pathways?

\footnotetext{
1 The current status of the submitted INDCs can be found under http://www4.unfccc.int/submissions/indc/ Submission\%20Pages/submissions.aspx.
} 
3. How do reduction efforts of other countries that are comparable to the reduction effort of the EU $40 \%$ target relate to their announced INDCs?

In order to assess the above questions, several effort-sharing approaches are applied to allocate emission reduction commitments among regions. There is a vast literature on effort-sharing approaches (for an overview, see Höhne et al. 2014; Clarke et al. 2014; Gupta et al. 2007), in which may different approaches are proposed according to many different equity principles. However, to our knowledge and based on the overview literature, all the existing effort-sharing approaches have the same global starting point, which can be an emission target, a target for long-term GHG concentrations, or a maximal temperature increase such as $2{ }^{\circ} \mathrm{C}$. Based on this global target the relevant parameters (like per-capita convergence level) of the approach are determined, and finally the allocation of the emission allowances (or emission reductions) across countries is calculated.

We adopt a new method of effort sharing by taking the EU target, instead of a global target, as starting point to determine the relevant parameters. In our approach, global emissions are the outcome of the effort-sharing approach (Fig. 1). We argue that this approach is better suited to assess which targets of other countries are comparable to a proposed reduction target of a specific country, and in how far a proposed reduction target is consistent with the $2{ }^{\circ} \mathrm{C}$ climate goal. This approach can be applied to the INDCs of all countries, but in this paper we focus specifically on the INDC of the EU as example of how this approach can be applied. Our approach is complementary to the standard effort-sharing approach of starting with a global target. For assessing how much individual regions should contribute to emission reductions to achieve a global target, the standard effort-sharing approach is better suited, but we argue that our approach is better suited for analyzing the fairness and ambition levels of INDCs relative to each other.

Apart from the different approach, this paper presents an update of earlier work by focusing on post-2020 INDCs. To our knowledge, the only studies focusing on INDC assessments using effort-sharing approaches are Meinshausen et al. (2015) and the online assessment by Climate Action Tracker (http://climateactiontracker.org/). The Climate Action Tracker takes as starting point a $2{ }^{\circ} \mathrm{C}$ global emission pathway, and our approach can be regarded as complementary to this study. The approach of Meinshausen et al. has some similarities with ours, it involves a major economy country taking the lead, and in a

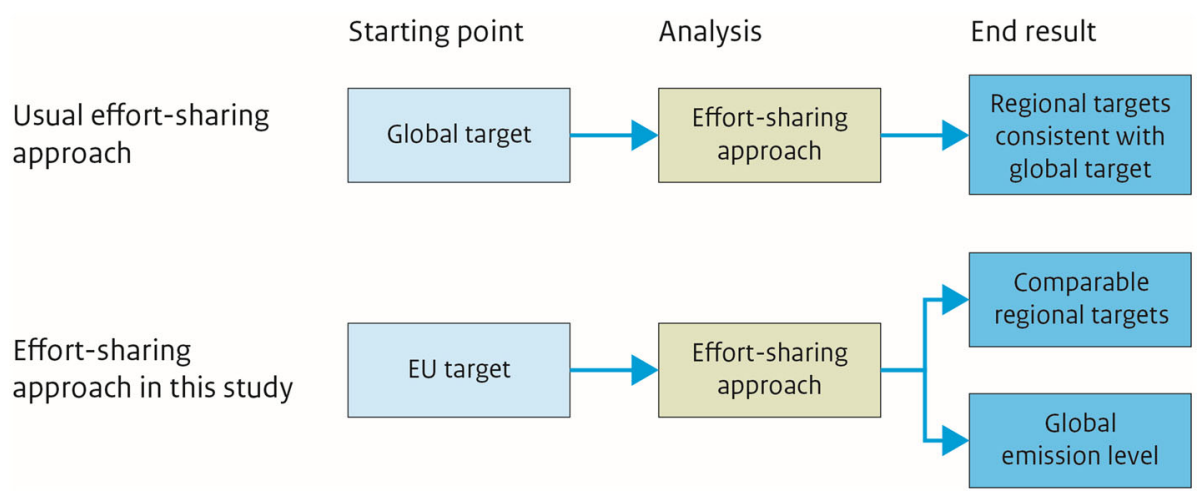

Fig. 1 Effort-sharing approach used in this study 
bottom-up manner, other countries then determine what they consider a fair comparable target, based on a "per-capita convergence" or "equal cumulative per-capita" approach.

This paper is organized as follows. Section 2 introduces the effort-sharing approaches applied in this study and describes the main assumptions and the methodology of calculating the emission reduction targets and abatement costs. Section 3 provides the results, and Sect. 4 provides a discussion and concludes.

\section{Methods}

\subsection{Effort-sharing approaches}

A vast number of effort-sharing approaches have been proposed in literature (see, for instance, den Elzen et al. 2007; Chakravarty et al. 2009; Baer et al. 2009; Pan et al. 2014c; Gupta and Bhandari 1999; Höhne et al. 2006; Ringius et al. 1998; Bode 2004; Russ and Criqui 2007; Meyer 2000; BASIC Experts 2011). Each of these proposed effort-sharing approaches is guided by some sort of equity principle according to Article 3.1 of the UNFCCC and has applied in some form the principle of CBDR-RC. There have also been several attempts in organizing effort-sharing approaches according to their equity principle and in analyzing the outcomes of approaches (Rose et al. 1998; Höhne et al. 2014; Clarke et al. 2014; Pan et al. 2014a, b; den Elzen and Lucas 2005; van Ruijven et al. 2012a, b; Ringius et al. 1998, 2002; Meinshausen et al. 2015; Raupach et al. 2014; Hof and den Elzen 2010).

This paper does not aim to contribute to this discussion, but rather at covering the range of proposals that are being discussed by Parties under the convention. As argued by Meinshausen et al. (2015), this range can be reasonable well covered by two effort-sharing approaches: common but differentiated convergence (CDC, Höhne et al. 2006) which is a modified per-capita convergence approach, and an approach based on historical responsibility.

Under the CDC approach, per-capita emission allowances of countries converge from current levels to an equal level for all countries, but differentiated over time. Like Höhne et al. (2006), we assumed a convergence time of 40 years. Regions start their convergence if their per-capita GHG emission level reaches a certain threshold level, which for this paper is set at the global average per-capita emission level. If per-capita emissions are below the global average, regions can follow their baseline emissions until their per-capita emissions reach the global average level. As 2030 is exactly midway in the convergence period, this implies that for regions above this threshold value in 2010 , the difference in per-capita emission levels of non-EU regions with the level of the EU has halved between 2010 and 2030. Under our population projections, the $40 \%$ EU target leads to a per-capita emission level of $6.5 \mathrm{tCO}_{2} \mathrm{eq}$ by 2030, compared to $9.5 \mathrm{tCO}_{2} \mathrm{eq}$ in 2010 . The per-capita emission level of, for instance, the USA was $21.3 \mathrm{tCO}_{2} \mathrm{eq}$ in 2010 or $11.8 \mathrm{tCO}_{2} \mathrm{eq}$ above the level of the EU. This implies that the per-capita emission target level of the USA under our $\mathrm{CDC}$ approach is $6.5 \mathrm{tCO}_{2}$ eq plus half of $11.8 \mathrm{tCO}_{2} \mathrm{eq}$, which equals $12.4 \mathrm{tCO}_{2}$ eq by 2030 .

Historical responsibility is seen as a key criterion by the BASIC countries (BASIC Experts 2011). The idea to set differentiated emission reduction targets according to the impact of historic emissions on temperature rise was argued for by Brazil, together with a simple methodology for illustrative purposes (UNFCCC 1997). However, there have been many different proposals to implement an effort-sharing approach based on historical 
responsibility since then (Rive et al. 2006; BASIC Experts 2011; den Elzen et al. 2005). Moreover, it matters strongly whether historical responsibility is interpreted as "proportional" or "conceptual." Quoting Friman and Strandberg (2014): "The conceptual view treats historical responsibility in a manner that avoids direct linkage between past emissions and present responsibilities. It typically looks at the present unequal distribution of capacity to act, and argues that the history of the creation of this distribution must be evaluated in moral terms. (...) The proportional view, on the other hand, defines responsibility in proportion to historical contribution." Many developed countries have started to interpret historical responsibility in conceptual terms, while most developing countries interpret the concept in proportional terms. Although both interpretations are legitimate under the UNFCCC, we choose the proportional interpretation, as this leads to an outcome which better captures the range of effort-sharing approaches we aim to explore in this study. Given this interpretation, one of the most important choices is the time period that is considered for cumulative emissions. ${ }^{2}$ Again, as we are interested in capturing the range of effort-sharing approaches and earlier start years generally lead to higher reduction requirements for high-income countries, we use an early start year of 1850 for determining cumulative GHG emissions. The historical emissions (including all GHGs) were based on the EDGAR dataset (JRC/PBL 2012) for the period 1970-2010 and on the MATCH dataset (Höhne et al. 2011) for the period 1850-1970, as described in den Elzen et al. (2013b). These data are publicly available. ${ }^{3}$ We follow Rive et al. (2006) with regard to the allocation methodology, which implies that a countries' required deviation from the baseline (see Sect. 3.2) is given by the countries' cumulative emissions between 1850 and 2010 relative to those of the EU, times the deviation of the baseline for the EU for achieving its $40 \%$ reduction target (see Eqs. 1 and 2 and Supplementary Information for calculations). This implies that the global emission reduction is a direct function of the deviation from baseline of the EU and the cumulative share of global emissions of the EU.

$$
E_{r}=\sum_{t=1850}^{2010} e_{r t}
$$

where $E_{r}$ are total cumulative emissions in $\mathrm{MtCO}_{2}$ eq in region $r$ and $e_{r t}$ are annual emissions in region $r$ at year $t$

$$
R R_{r t}=\frac{E_{\mathrm{r}}}{E_{\mathrm{EU}}} R R_{\mathrm{EU}_{t}}
$$

where $R R_{r t}$ is the deviation of the baseline in region $r$ at year $t$ and $R R_{\mathrm{EU} t}$ is the deviation of the baseline in the EU at year t (both in $\mathrm{MtCO}_{2} \mathrm{eq}$ ).

We compare the CDC and historical responsibility approach with two allocations based on mitigation costs. The first is our main reference case, in which marginal abatement costs are equalized in all regions. This reference case is included in this study for comparison, as it results in the most efficient way to reduce emissions, without being based on a specific equity principle. As the burden of a carbon tax tends to fall on those regions with high emission intensities or with a large potential to reduce emissions (Hof et al. 2009), this approach leads to relatively high reduction targets for developing countries. Under the second approach, emission allowances are distributed in such a way that equal relative

\footnotetext{
${ }^{2}$ For simplification, we use cumulative greenhouse gas emissions as proxy for contribution to climate change (den Elzen et al. 2013b).

3 http://www.pbl.nl/en/publications/countries-contributions-to-climate-change.
} 
costs as share of GDP are the same across regions. The common cost level was again determined using the expected direct cost of achieving the EU $40 \%$ domestic GHG emission reduction target (Sect. 3). We have applied this approach using the same method as was used in the model intercomparison project LIMITS (Kriegler et al. 2013; see Supplementary Information for details). Although the equal relative costs method has been proposed as operational rule of the ability to pay criterion by Rose et al. (1998), it does not lead to equal welfare impacts as the same fraction of GDP is valued differently in countries with different income levels. We therefore mainly included the results of such an allocation to provide insight into regional cost differences assumed by our marginal abatement cost (MAC) curves (see Sect. 2.2).

In the calculations, it is assumed that all regions should reach the 2030 emission reduction targets resulting from the effort-sharing approaches through domestic emission reduction (no purchasing of emission credits was allowed). This is also the reason why we have excluded approaches which lead to emission allocations which are higher than projected baselines. Many resource-sharing approaches (i.e., approaches that allocate allowances instead of reduction requirements) are of this nature, such as the equal cumulative emission per-capita principle (Pan et al. 2014c; Pan 2005). Since we are interested in comparing domestic emission targets, we do not allow for emission trading. Therefore, we do not take into account resource-sharing approaches that lead to emission allocations higher than baseline levels in our analysis.

\subsection{Model framework for determining emission targets and abatement costs}

The integrated modeling framework FAIR (den Elzen et al. 2014) was used for calculating emission targets and abatement costs. This model uses information on marginal abatement costs (MAC) of reducing (1) energy- and industry-related $\mathrm{CO}_{2}$ emissions from the energy model TIMER (Chapter 4.1 of Stehfest et al. 2014), (2) $\mathrm{CO}_{2}$ emissions from forestry from the G4M model (Kindermann et al. 2008), and (3) non- $\mathrm{CO}_{2} \mathrm{GHG}$ emissions from a variety of sources, including EPA (2013), Lucas et al. (2007), and Graus et al. (2004) for methane and nitrous oxide, and Schwarz et al. (2011) for the fluorinated GHGs (HFCs, PFCs and SF6), see Supplementary Information for more detail. The non- $\mathrm{CO}_{2} \mathrm{MAC}$ curves have been made consistent with the baseline used in this study (Sect. 3.2). In addition, the MAC curves have been made time dependent to account for technology change and the removal of implementation barriers, based on the method of Lucas et al. (2007). To analyze the uncertainty in results, we included an analysis of energy- and industry-related $\mathrm{CO}_{2} \mathrm{MAC}$ curves from Enerdata's POLES energy model ${ }^{4}$ (Enerdata 2010).

The energy- and industry-related $\mathrm{CO}_{2}$ MAC curves were determined by imposing a carbon tax in the TIMER model and recording the induced reduction in $\mathrm{CO}_{2}$ emissions. The model's behavior is mainly determined by the substitution processes of various technologies based on long-term prices and fuel preferences. These two factors drive multinomial logit models that describe investments in new energy production and consumption capacity. The demand for new capacity is limited by the assumption that capital goods are only replaced at the end of their technical lifetime. The long-term prices that drive the model are determined by resource depletion and technology development. Resource depletion is important for both fossil fuels and renewables (for which depletion and costs depend on annual production rates). Technology development is determined

\footnotetext{
${ }^{4}$ See http://www.enerdata.net/enerdatauk/knowledge/subscriptions/forecast/marginal-abatement-cost-curvesMACCs.php.
} 
using learning curves or through exogenous assumptions. Emissions from the energy system are calculated by multiplying energy consumption and production flows by emission factors. A carbon tax can be used to induce a dynamic response, such as the increased use of low- or zero-carbon technologies, energy efficiency improvements, and end-of-pipe emission reduction technologies.

The MAC curves from forestry activities (deforestation, afforestation, and reforestation) were derived by introducing a carbon price in the IIASA's G4M and GLOBIOM forestry model (Böttcher et al. 2011; Kindermann et al. 2008), which means that (1) forest owners are paid for any carbon that is stored in forest living biomass above baseline level, and (2) they have to pay a tax if the amount of carbon in forest living biomass is below the baseline level. G4M is a geographically explicit agent-based model to assess afforestation, deforestation, and forest management decisions at 30 arcminutes level (equal to $1.86 \mathrm{~km}$ at the equator). The model uses recent baseline projections based on results of the POLES energy model for future bioenergy demand and related assumptions on population growth, economic development (GDP) (Böttcher et al. 2011). The most important parameters of G4M are mean annual increment, maximum share of saw logs in the mean annual increment, and harvesting cost. Mitigation measures considered in the G4M model include reducing deforestation, increasing afforestation, changes in rotation lengths of existing managed forests, changes in the ratio between thinning and final fellings, and changes in harvest intensity.

For cost calculations for 2030, we see that the potential for reducing $\mathrm{CO}_{2}$ emissions from forestry activities will be fully used for both developed and developing regions (Angelsen et al. 2014). As the mitigation costs of these activities are often lower than reducing emissions in other sectors, $\mathrm{CO}_{2}$ emissions from land use are reduced more than the average reductions in all sectors, especially for Brazil, Indonesia, Australia and New Zealand, and Russia.

To explore the consequences of the uncertainty in cost estimates, we also used energyand industry-related $\mathrm{CO}_{2}$ MAC curves information from the POLES energy model (Russ and Criqui 2007; Russ and van Ierland 2009). The POLES version of Enerdata (2010) is used. The POLES $\mathrm{CO}_{2}$ MAC curves were selected for the uncertainty analysis since: (1) both TIMER and POLES have information at the level of multiple sectors and world regions (both Annex I and non-Annex I), so can be incorporated in our integrated model; (2) both models show a wide range of outcomes across various models for Annex I as a group (Fig. 3.1 in Amann et al. 2009). The dynamics of the POLES model are based on a recursive simulation process of energy demand and supply with lagged adjustments to prices and a feedback loop through the international energy price. The model is developed in the framework of a hierarchical structure of interconnected modules at the international, regional, and national levels. It contains technologically detailed modules for energyintensive sectors, including power generation, iron and steel, the chemical sector, aluminum production, cement making, non-ferrous minerals, and modal transport sectors. All energy prices are determined endogenously. Long-term oil prices depend primarily on the relative scarcity of oil reserves.

FAIR distinguishes 26 world regions, including the individual countries the USA, Canada, Russia, Japan, India, Brazil, and Mexico. The region Indonesia includes East Timor and Papua New Guinea, the region China includes Mongolia, Taiwan, Hong Kong, and Macau, and the region Oceania includes Australia and New Zealand. Europe is modeled as two separate regions: Western and Central Europe. Together, they represent the EU28 and Norway, Switzerland, Iceland, Albania, and the former Yugoslavian states. This implies that FAIR has a somewhat broader than formal definition of the EU. However, in 
terms of total GHG emissions the EU28 and the FAIR region Western and Central Europe are very close, the difference being about $0.25 \mathrm{GtCO}_{2} \mathrm{e}$ (about $5 \%$ ) in $2010,{ }^{5}$ and as such this small difference in regional breakdown does not have a large effect on the results.

\subsection{Baseline}

The IMAGE model framework was used to create a middle-of-the-road baseline scenario. The baseline is based on the SSP2 storyline (O'Neill et al. 2014) and includes all Kyoto GHG emissions. For the energy- and industry-related $\mathrm{CO}_{2}$ MAC curves from POLES, we use the POLES baseline emissions from this sector as these are calibrated to this specific baseline. The POLES baseline is broadly similar to the reference scenario of the IEA World Energy Outlook (IEA 2009) and has been corrected for the economic crisis. In both the IMAGE and POLES baselines, the largest absolute increase in GHG emissions occurs in China and India, whereas emissions in most developed countries more or less stabilize at 2010 levels by 2030. The projected global GHG emission level, including emissions from international shipping but excluding emissions from international aviation, is about $61 \mathrm{GtCO}_{2} \mathrm{eq}$ in 2030 in the IMAGE baseline and $62 \mathrm{GtCO}_{2} \mathrm{eq}$ in the POLES baseline, compared with about $48 \mathrm{GtCO}_{2} \mathrm{eq}$ in 2010. The Supplementary Information shows more background information about the assumed baseline emissions for the regions included in our study.

The more recently developed IMAGE baseline is better calibrated with recent emission trends and renewable installed capacities than the POLES baseline. A consequence is that under the IMAGE baseline, less mitigation effort for the EU is required to achieve the $40 \%$ EU target compared to the POLES baseline. More specifically, in the IMAGE baseline EU emissions by 2030 equal $24 \%$ below 1990 levels, while in the POLES baseline it equals only $8 \%$ below 1990 levels.

For this study, baseline data-except data from POLES and land-use $\mathrm{CO}_{2}$ emissions-were harmonized to match historical emission levels for the 1990-2010 period. The historical dataset includes the Kyoto GHGs $\mathrm{CO}_{2}, \mathrm{CH}_{4}, \mathrm{~N}_{2} \mathrm{O}$, HFCs, PFCs, and SF6. The data for the Annex I countries are based on the 2012 national emission inventories submissions to the UNFCCC. For all non-Annex I countries, energy-related $\mathrm{CO}_{2}$ emissions from IEA (2012) and non-energyrelated emissions from EDGAR 4.2 (JRC/PBL 2012) were used. Harmonization was carried out by applying regional harmonization ratios in 2010 to match the total GHG emission level of the baseline to that of the historical dataset. Harmonization ratios converge from 2010 levels to unity in 2100. Our historical emissions slightly differ to those of the UNFCCC submissions, because (1) we used global warming potentials (GWPs) from the IPCC AR4 report (Forster et al. 2007) to aggregate emissions of different GHGs to $\mathrm{CO}_{2}$ equivalents, whereas the UNFCCC used GWPs from the IPCC SAR report (UNFCCC 1995), and (2) we base $\mathrm{CO}_{2}$ emissions from land use on the forestry model G4M, whereas the UNFCCC used national submissions for these $\mathrm{CO}_{2}$ emissions. The POLES baseline has not been harmonized to historical datasets, as the MAC curves from POLES are calibrated to the unharmonized baseline.

\section{Results}

The results are presented according to our three research questions. First, the comparable targets for other major economies to the INDC of the EU will be presented, followed by an assessment of the resulting global emission level with the emission level consistent with a

\footnotetext{
5 According to the EDGAR database: http://edgar.jrc.ec.europa.eu/, accessed 11 November 2015.
} 
$2{ }^{\circ} \mathrm{C}$ pathway. Finally, the results from the effort-sharing approaches are compared to the INDCs of the major economies.

\subsection{Comparable regional emission targets}

Table 1 shows which targets for other major economies are comparable to the domestic EU $40 \%$ target according to the two effort-sharing approaches and the two allocations based on costs. The results are given both relative to 2010 levels and 2030 baseline levels (both IMAGE and POLES baselines). Although the target of the EU was set to $40 \%$ below 1990 level for both the POLES and IMAGE baselines, keep in mind that the reductions compared to the model baseline differ quite substantially, as the EU baseline reaches $24 \%$ below 1990 levels in the IMAGE baseline and only $8 \%$ under 1990 levels in the POLES baseline.

As the per-capita baseline emission levels of India, Indonesia, and Mexico are still below the global average by 2030, these countries do not have to reduce their emissions according to the CDC approach. In our baselines, all countries shown in Table 1 except for the three just mentioned have per-capita emissions which are higher than those of the EU by 2030 . Therefore, the reductions compared to baseline are also higher. In short, as percapita emissions of the EU are relatively low given its income level, for other industrialized regions and China the CDC approach leads to more ambitious reduction targets by 2030 than the EU compared to baseline.

The approach based on historical responsibility shows a completely different picture. Under this approach, the reduction targets depend on the region's cumulative emissions in the period 1850-2010 relative to those of the EU (see Sect. 2). The EU was responsible for about $18 \%$ of global cumulative emissions in this period. The USA was responsible for a similar share and therefore receives similar reduction requirements in absolute terms. As current and future projected emissions are higher for the USA than for the EU, the reductions relative to 2010 and baseline levels are lower than the EU. A similar reasoning holds for the other regions, and therefore, the historical responsibility approach leads to reduction targets for other regions which are in general less stringent compared to baseline than the INDC of the EU. An exception is Indonesia, which is due to its relatively high historical $\mathrm{CO}_{2}$ emissions as a consequence of deforestation.

Both the CDC and historical responsibility approach lead to lower reduction targets for the least developed countries India, Indonesia, and Mexico compared to a cost-optimal allocation of the emission reductions (equal carbon tax). For all other regions, an optimal allocation leads to allowances somewhere in between the CDC and historical responsibility approach with the exception of Brazil, which has a large relatively cheap potential to mitigate $\mathrm{CO}_{2}$ emissions by reducing deforestation. The equal cost approach leads to lower reduction targets (compared to baseline) than the EU for those countries with a higher potential than the EU to reduce emissions at the given carbon price. A good example is India, which for a given carbon price has relatively high mitigation costs as its potential to reduce emissions is high. The area under the MAC curve is therefore larger than for the EU at a given carbon price. In order to arrive at the same relative costs as the EU, the emission reduction target has to be set much lower than under the optimal allocation.

\subsection{Projected global emissions compared to $2{ }^{\circ} \mathrm{C}$}

In the baseline, global emissions are projected to be $61-62 \mathrm{GtCO}_{2}$ eq by 2030 . According to UNEP (2014), the global emission level by 2030 consistent with least-cost emission 


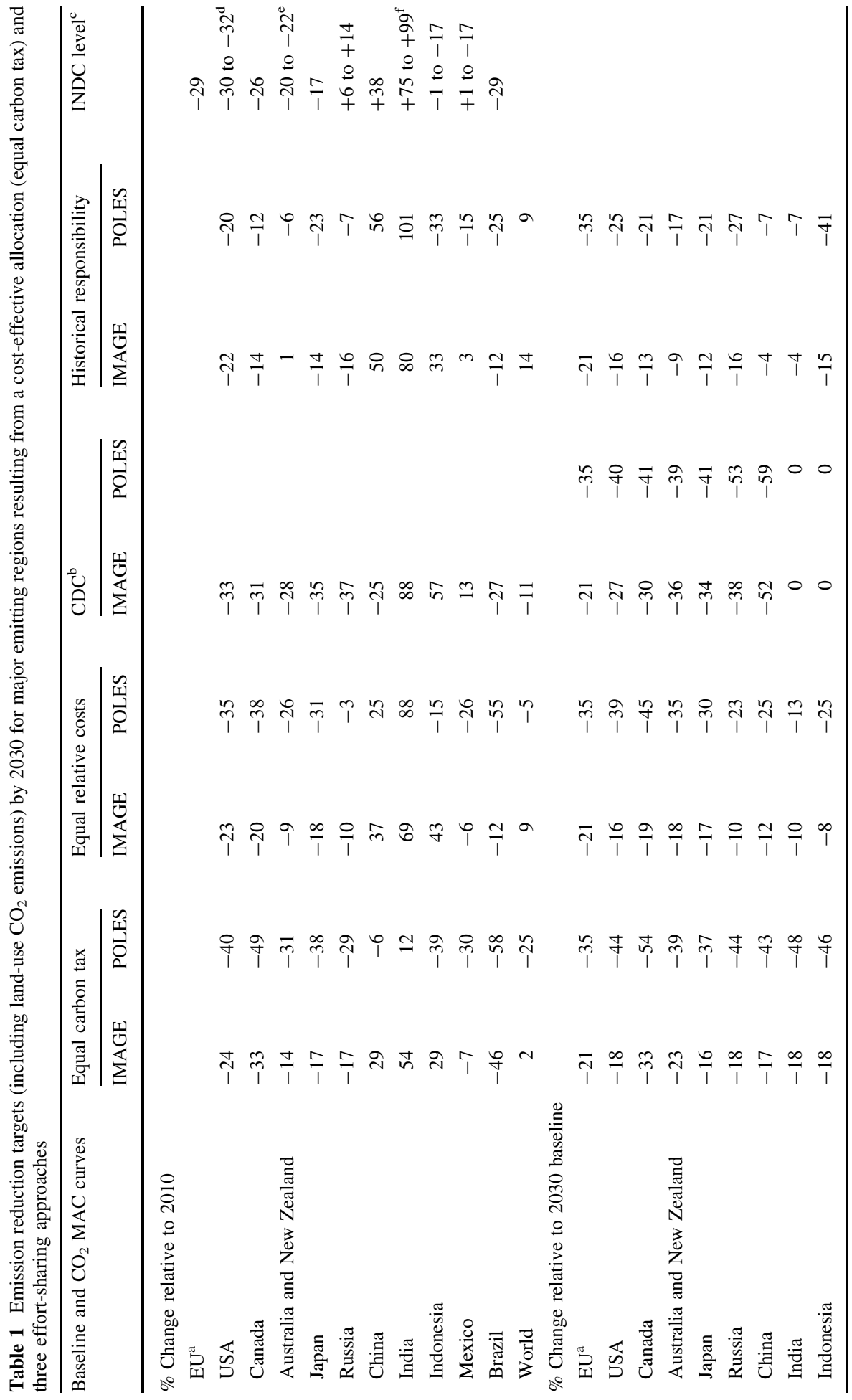




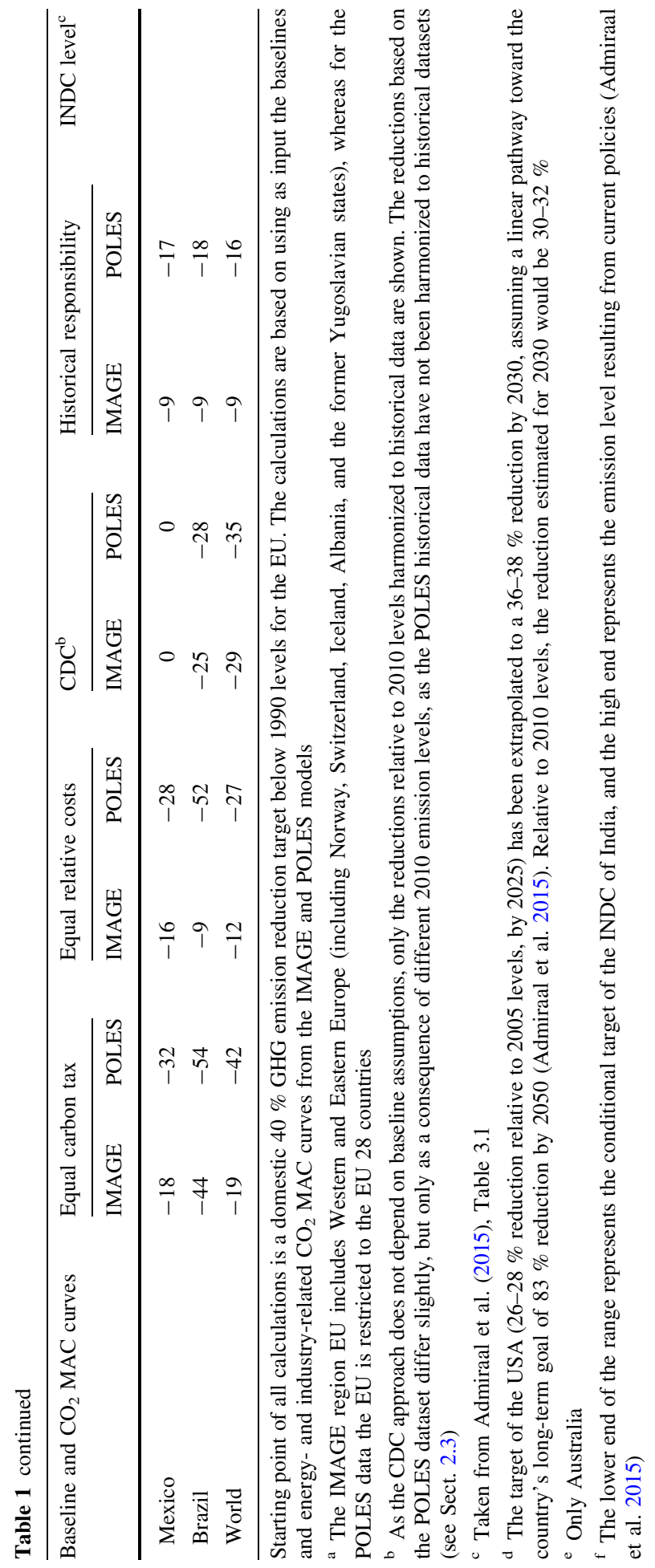


pathways to keeping global temperature increase below $2{ }^{\circ} \mathrm{C}$ with a likely $(>66 \%)$ probability is $30-44 \mathrm{GtCO}_{2} \mathrm{eq}$, with a median estimate of $42 \mathrm{GtCO}_{2}$ eq. These pathways assume immediate climate action in all countries and sectors from 2020 onward, starting from emission levels resulting from the countries' current pledges for 2020.

With a cost-optimal allocation based on an equal carbon tax, global emissions are estimated at $36.0 \mathrm{GtCO}_{2} \mathrm{eq}$ (POLES baseline and $\mathrm{CO}_{2}$ MAC curves) to $49.4 \mathrm{GtCO}_{2} \mathrm{eq}$ (IMAGE baseline and TIMER MAC curves; Fig. 2). This large difference is the result of (1) higher EU baseline emissions according to POLES than IMAGE, resulting in a larger EU mitigation effort under the POLES baseline, and (2) POLES assuming more potential in developing regions and less in developed regions than TIMER, at a given carbon price. Both factors result in a much higher carbon price needed to achieve the EU 2030 target under the POLES baseline and $\mathrm{CO}_{2}$ MAC curves than under the IMAGE baseline and TIMER $\mathrm{CO}_{2}$ MAC curves. As for all other regions the same carbon tax as the EU is applied, this results in a much lower global emission level under the POLES baseline and $\mathrm{CO}_{2}$ MAC curves.

Under the CDC approach, projected 2030 global emission levels are within the range for a likely chance of achieving $2{ }^{\circ} \mathrm{C}$. As this method does not depend on baseline emissions or mitigation costs, the difference between the POLES (40.0 $\mathrm{GtCO}_{2}$ eq) and IMAGE (43.2 $\mathrm{GtCO}_{2} \mathrm{eq}$ ) baseline is relatively low. CDC leads to relatively high reductions compared to the equal relative costs method because per-capita emissions of the EU are low compared with countries such as the USA, Canada, Russia, and Australia and New Zealand. As every country converges to the same per-capita emissions level, countries with high per-capita emissions need to reduce more to achieve their target, leading to a higher global reduction.

The historical responsibility approach leads to global emission levels above those which are consistent with $2{ }^{\circ} \mathrm{C}$ pathways. There are two major reasons for this. First of all, the EU has a relatively large share in global cumulative emissions between 1850 and 2010 and therefore this approach leads to relatively stringent targets for the EU compared to other

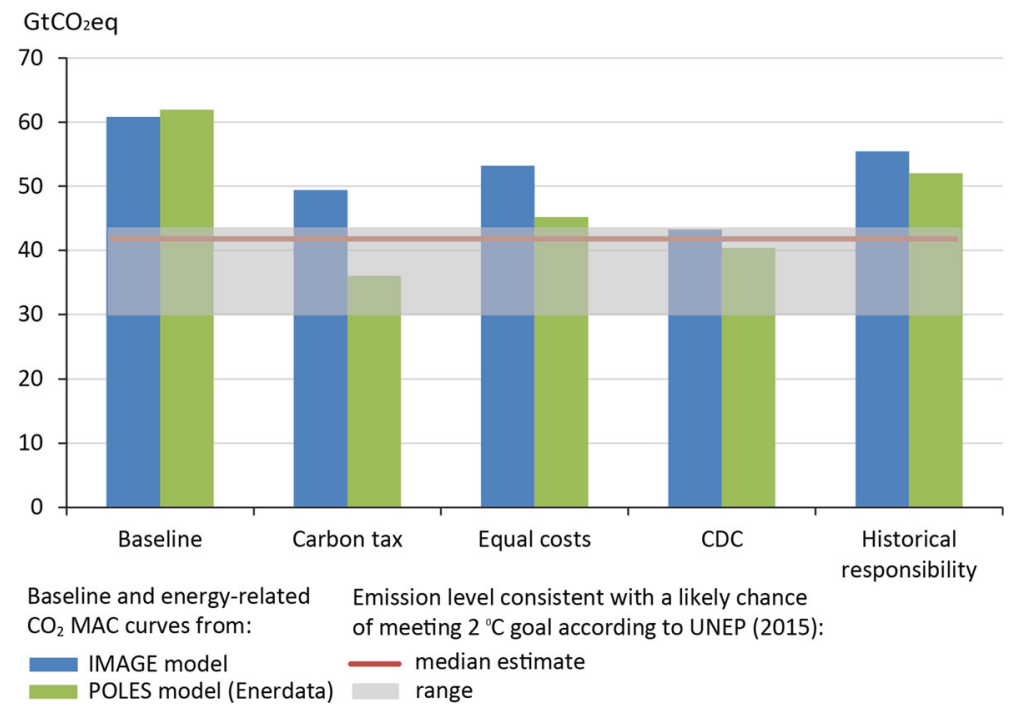

Fig. 2 Global GHG emissions by 2030 resulting from the effort-sharing approaches compared to the likely range consistent with least-cost emission pathways with a likely chance of meeting $2{ }^{\circ} \mathrm{C}$ (the latter of which based on UNEP (2015)) for the IMAGE and POLES baselines and MAC curves 
approaches such as CDC (see Sect. 3.1; Table 1). Secondly, especially for the IMAGE baseline an additional explanation is that the baseline emissions of the EU are already substantially below 1990 levels by 2030, so that the deviation from baseline is relatively small. As the required reductions for the other regions not only depend on their cumulative emissions between 1850 and 2010, but also on the reduction of the EU (see Eqs. 1 and 2), all other regions also face relatively low reduction requirements.

The projected reductions under the equal relative costs approach strongly depend on baseline assumptions and MAC curves, for the same reasons as they did for the carbon tax. However, total reductions are less than under a carbon tax, so that under both baselines and MAC assumptions the reductions are not sufficient for achieving the reductions that are required for a $2{ }^{\circ} \mathrm{C}$ pathway, with projected global emission levels of about 45 and 53 $\mathrm{GtCO}_{2}$ eq. The reason that equal relative costs lead to higher global emission levels than a carbon tax is that the impact on mitigation costs of a given carbon tax is lower in developed countries than in developing countries, due to the higher potential being available in the latter group (Hof et al. 2009). Therefore, if in all countries the same carbon tax as the EU is applied, mitigation costs as share of GDP is (much) higher in developing countries. From this automatically follows that if all countries have the same mitigation costs as share of GDP, total emission reductions are lower.

\subsection{Comparison of INDCs}

Our third research question is how the "comparable" reduction targets given in Table 1 compare to the countries' submitted INDCs. The reductions of the INDCs were based on Admiraal et al. (2015; Table 3.1). For those countries that have not specified a reduction target for 2030, such as the USA, the reduction for 2030 was estimated by assuming that long-term targets for the year 2050 will be achieved by a linear reduction pathway from the emission level resulting from the INDC (in the case of the USA, 2025). Figure 3 compares

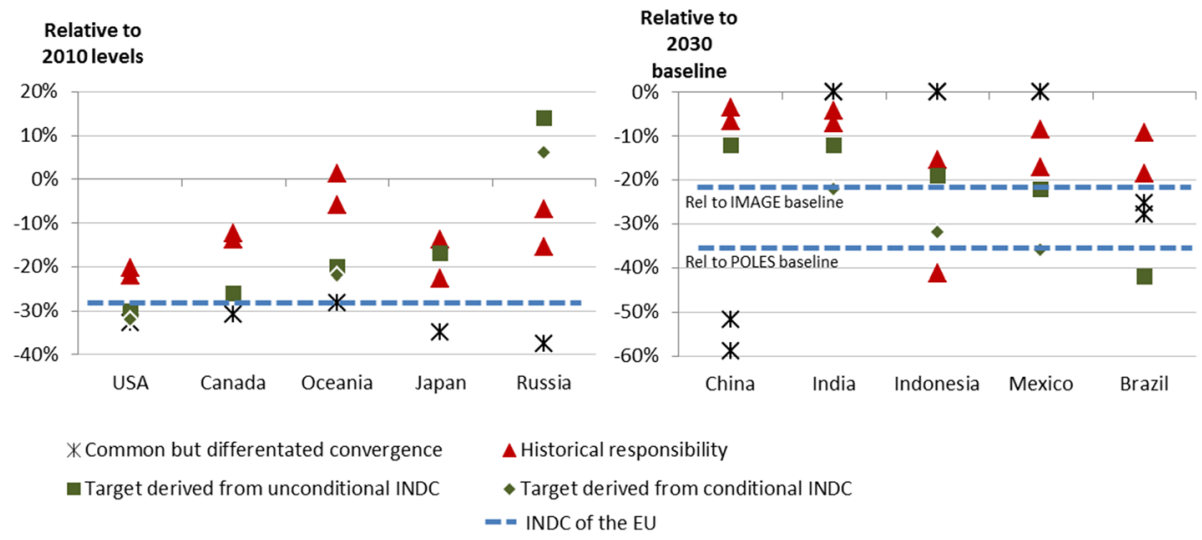

Fig. 3 Range in 2030 GHG emission reduction targets resulting from the effort-sharing approaches (Table 1) compared to derived targets for 2030 based on submitted INDCs (based on Table 3.1 of Admiraal et al. 2015), presented relative to 2010 levels for the high-income countries, and relative to IMAGE or POLES baseline for the low-income countries and emerging economies. Both the conditional and unconditional INDCs are shown for those countries that submitted both. For the effort-sharing targets, the results of the IMAGE and POLES baselines and $\mathrm{CO}_{2}$ MAC curves are shown. The dotted blue line shows the $40 \%$ EU target for comparison (as the IMAGE and POLES differ with respect to the EU baseline, both the reductions relative to the IMAGE and POLES baselines are shown) 
the INDC targets for 2030 with the range resulting from the effort-sharing approaches CDC and historical responsibility. For the high-income countries, reductions are presented relative to 2010 emission levels, whereas for low-income countries and emerging economies, reductions are relative to 2030 baseline levels. Indonesia and Mexico submitted an unconditional and a more ambitious conditional INDC, both of which are shown in the figure. For India, we have assumed, as in Admiraal et al. (2015), that the conditional INDC includes the effects of India's greenhouse gas intensity target, non-fossil electricity target, as well as the carbon sink target. The unconditional INDC only includes the effect of the greenhouse gas intensity target, but as the latter is not limiting, the emission level resulting from current policies is shown here.

As we have deliberately chosen two effort-sharing approaches that cover the range of the political debate, the range in emission reduction targets resulting from the two effortsharing approaches is very large for most countries. Therefore, most of the reduction efforts implied by the INDCs are within the range resulting from the effort-sharing approaches. Of the high-income countries, only Russia has submitted an INDC which is less stringent than the effort-sharing range based on the INDC of the EU. The INDCs of Canada and Oceania are relatively close to the high end of the effort-sharing range, while Japan is close to low end of the effort-sharing range.

Interestingly, of the major low-income and emerging economies included in this study, India, Mexico, and Brazil have more ambitious INDCs than what results from both effortsharing approaches. As Mexico and India have baseline per-capita emissions which remain below the global average until 2030, the CDC approach does not imply reduction targets for these countries. Furthermore, their historical responsibility is relatively low so that both effort-sharing approaches lead to relatively low reduction targets. Moreover, the INDCs of Mexico and Brazil imply substantial reductions compared to baseline.

Comparing these results with the analysis by Climate Action Tracker (CAT, http:// climateactiontracker.org/, as of November 19, 2015) shows some similarities, but also some differences. Most importantly, CAT calculates the reduction targets based on a wide range of effort-sharing approaches for meeting the $2{ }^{\circ} \mathrm{C}$ goal, whereas here the considered effort-sharing approaches do not necessarily meet this goal. CAT rates the INDC of the EU as "medium," and Mexico, India, Brazil, and China receive the same rating. This is broadly in line with the results as shown by Fig. 3 and Table 1. CAT rates the INDC of Russia as inadequate, which is also in line with our results. The differences are for Japan, Australia, Canada, Indonesia, and Japan. CAT rates the INDCs of these countries as inadequate, a rating which does not immediately seems in line with our results, although a direct comparison is not possible as the CAT uses a different approach than ours. Even so, an important reason seems to be that the historical emissions of these countries in the period 1850-2010 are also relatively high, but similar to those of the EU, and therefore according to this approach the INDCs do not underperform in ambition level compared to the EU. If we would rate the INDC of the EU according to historical responsibility, we would also arrive at an inadequate rating for the EU, based on Fig. 2.

\section{Discussion and conclusions}

There is a large body of literature that applies effort-sharing approaches to provide insight into fair regional contributions to climate change mitigation, given a specified global climate goal. In this study, a novel approach is introduced that starts with a specified 
regional target (in our case, the INDC of the EU) and applies effort-sharing to determine comparable targets for other regions. The global mitigation effort is an outcome, not a starting point, of our analysis. This approach is well suited to address the relative ambition level of INDCs. We have applied this approach to assess the fairness and ambition level of the EU's INDC, but it can also be applied to frame reduction targets of other regions. Moreover, other effort-sharing approaches could be included if countries wish to compare their INDC according to a specific effort-sharing approach.

One important caveat is that, although we have selected two effort-sharing approaches that cover the political range reasonably well (CDC and historical responsibility based on cumulative emissions between 1850 and 2010), there are other effort-sharing approaches that lead to results which are outside the range of the effort-sharing approaches which we have applied. Therefore, a broader selection of effort-sharing approaches may result in a wider range of regional targets and consequently of global emission levels resulting from these targets. This is especially the case for resource-sharing approaches that lead to surplus emission allowances or allowance levels that exceed baseline emission projections. We have, however, deliberately not taken such effort-sharing approaches into account as the aim is to assess the INDC of the EU, which only consist of a domestic emission reduction target. The possibility of emission trading is therefore excluded from the analysis.

Concluding, we have found that the INDCs of the USA, Canada, Australia, Japan, China, and Indonesia are largely comparable to the INDC of the EU, based on the range resulting from a CDC and a historical responsibility approach. The INDC of Russia seems less ambitious than the INDC of the EU. Interestingly, the INDCs of India, Mexico, and Brazil are more ambitious than the INDC of the EU, both according to a CDC and a historical responsibility effort-sharing approach. According to a CDC effort-sharing approach, the INDC of the EU could well be consistent with a $2{ }^{\circ} \mathrm{C}$ emission pathway. However, from a historical responsibility point of view, the INDC of the EU falls well short (about $10 \mathrm{GtCO}_{2}$ in 2030) of achieving a $2{ }^{\circ} \mathrm{C}$ emission pathway. This large difference is due to (1) relatively low and decreasing per-capita emissions of the EU, and (2) a relatively large contribution to global historical emissions. The first factor leads to relatively high reduction efforts for non-EU countries under a CDC approach, while the second factor leads to relatively low reduction efforts for non-EU countries under a historical responsibility approach.

Acknowledgments The research leading to these results has received funding from the European Union Seventh Framework Programme (FP7/2007-2013) under Grant Agreement No. 603942 (PATHWAYS).

\section{References}

Admiraal, A., den Elzen, M., Forsell, N., Turkovska, O., Roelfsema, M., \& van Soest, H. (2015). Assessing Intended Nationally Determined Contributions to the Paris climate agreement-What are the projected global and national emission levels for 2025-2030?. The Hague: PBL Netherlands Environmental Assessment Agency.

Amann, M., Rafaj, P., \& Höhne, N. (2009). GHG mitigation potentials in Annex I countries. Comparison of Model Estimates for 2020. Laxenburg, Austria. IR-09-034, IIASA.

Angelsen, A., Gierløff, C. W., Beltrán, A. M., \& den Elzen, M. (2014). REDD credits in a global carbon market: Options and impacts. Nordic Council of Ministers. 
Baer, P., Athanasiou, T., Kartha, S., \& Kemp-Benedict, E. (2009). Greenhouse development rights: A proposal for a fair global climate treaty. Ethics, Place and Environment, 12(3), 267-281.

BASIC Experts. (2011). Equitable access to sustainable development: Contribution to the body of scientific knowledge. Beijing, Brasilia, Cape Town and Mumbai: BASIC Expert Group.

Bode, S. (2004). Equal emissions per capita over time: A proposal to combine responsibility and equity of rights for post-2012 GHG emission entitlement allocation. European Environment, 14(5), 300-316.

Böttcher, H., Gusti, M., Mosnier, A., \& Havlik, P. (2011). Global forestry emissions projections and abatement costs: IIASA, Laxenburg, Austria, final report submitted to The Secretary of State of Energy and Climate Change, London (August 2011). http://www.iiasa.ac.at/publication/more_XO-11-051.php.

Chakravarty, S., Chikkatur, A., de Coninck, H., Pacala, S., Socolow, R., \& Tavoni, M. (2009). Sharing global $\mathrm{CO}_{2}$ emission reductions among one billion high emitters. Proceedings of the National Academy of Sciences, 106(29), 11884-11888.

Clarke, L., Jiang, K., Akimoto, K., Babiker, M., Blanford, G., Fisher-Vanden, K., et al. (2014). Assessing transformation pathways. In O. Edenhofer, R. Pichs-Madruga, Y. Sokona, E. Farahani, S. Kadner, K. Seyboth, et al. (Eds.), Climate Change 2014: Mitigation of climate change. Contribution of working group III to the fifth assessment report of the intergovernmental panel on climate change. Cambridge: Cambridge University Press.

Dellink, R., Briner, G., \& Clapp, C. (2011). The Copenhagen Accord/Cancun Agreements emissions pledges for 2020: Exploring economic and environmental impacts. Climate Change Economics, 2(1), 53-78.

den Elzen, M. G. J., Hof, A. F., Beltran, A. M., Grassi, G., Roelfsema, M., van Ruijven, B., et al. (2011). The Copenhagen accord: Abatement costs and carbon prices resulting from the submissions. Environmental Science \& Policy, 14(1), 28-39.

den Elzen, M. G. J., Hof, A. F., \& Roelfsema, M. (2013a). Analysing the greenhouse gas emission reductions of the mitigation action plans by non-Annex I countries by 2020. Energy Policy, 56, 633-643.

den Elzen, M., Hof, A., van den Berg, M., \& Roelfsema, M. (2014). Climate policy. In E. Stehfest, D. van Vuuren, T. Kram, \& L. Bouwman (Eds.), Integrated assessment of global environmental change with IMAGE 3.0. Model description and policy applications (pp. 303-311). The Hague: PBL Netherlands Environmental Assessment Agency.

den Elzen, M. G. J., Höhne, N., Brouns, B., Winkler, H., \& Ott, H. E. (2007). Differentiation of countries' future commitments in a post-2012 climate regime. An assessment of the "South-North Dialogue" proposal. Environmental Science \& Policy, 10(3), 185-203.

den Elzen, M. G. J., \& Lucas, P. L. (2005). The FAIR model: A tool to analyse environmental and costs implications of regimes of future commitments. Environmental Modeling and Assessment, 10(2), $115-134$.

den Elzen, M. G. J., Olivier, J. G. J., Höhne, N., \& Janssens-Maenhout, G. (2013b). Countries' contributions to climate change: Effect of accounting for all greenhouse gases, recent trends, basic needs and technological progress. Climatic Change, 121(2), 397-412.

den Elzen, M. G. J., Schaeffer, M., \& Lucas, P. (2005). Differentiating future commitments on the basis of countries' relative historical responsibility for climate change: Uncertainties in the 'Brazilian Proposal' in the context of a policy implementation. Climatic Change, 71(3), 277-301.

Enerdata. (2010). POLES model marginal abatement cost curves (MACCs) based on the World Energy Outlook 2009. http://www.enerdata.net/enerdatauk/subscriptions/marginal-abatement-cost-curvesMACCs.php.

EPA. (2013). Global mitigation of non- $\mathrm{CO}_{2}$ greenhouse gases: 2010-2030. EPA-430-R-13-011. http:// www.epa.gov/climatechange/Downloads/EPAactivities/MAC_Report_2013.pdf United States Environmental Protection Agency.

European Commission. (2014). Fact Sheet Climate Change 2014, http://ec.europa.eu/clima/publications/ docs/factsheet_climate_change_2014_en.pdf.

Forster, P., Ramaswamy, V., Artaxo, P., Berntsen, T., Betts, R., Fahey, D. W., et al. (2007). Changes in atmospheric constituents and in radiative forcing. In S. Solomon, D. Qin, M. Manning, Z. Chen, M. Marquis, K. B. Averyt, et al. (Eds.), Climate Change 2007: The physical science basis. Contribution of working group I to the fourth assessment report of the intergovernmental panel on climate change. Cambridge, New York, NY: Cambridge University Press.

Friman, M., \& Strandberg, G. (2014). Historical responsibility for climate change: Science and the sciencepolicy interface. Wiley Interdisciplinary Reviews: Climate Change, 5(3), 297-316.

Graus, W., Harmelink, M., \& Hendriks, C. (2004). Marginal GHG-abatement curves for agriculture. Utrecht: Ecofys.

Gupta, S., \& Bhandari, M. (1999). An effective allocation criterion for $\mathrm{CO}_{2}$ emissions. Energy Policy, 27(12), 727-736. 
Gupta, S., Tirpak, D. A., Burger, N., Gupta, J., Höhne, N., Boncheva, A. I., et al. (2007). Policies, instruments and co-operative arrangements. In B. Metz, O. R. Davidson, P. R. Bosch, R. Dave, \& L. A. Meyer (Eds.), Climate Change 2007: Mitigation. Contribution of working group III to the fourth assessment report of the intergovernmental panel on Climate Change. Cambridge: Cambridge University Press.

Hof, A. F., \& den Elzen, M. G. J. (2010). The effect of different historical emissions datasets on emission targets of the sectoral mitigation approach Triptych. Climate Policy, 10(6), 684-704.

Hof, A. F., den Elzen, M. G. J., \& Roelfsema, M. (2013). The effect of updated pledges and business-asusual projections, and new agreed rules on expected global greenhouse gas emissions in 2020. Environmental Science \& Policy, 33, 308-319.

Hof, A. F., den Elzen, M. G. J., \& van Vuuren, D. P. (2009). Environmental effectiveness and economic consequences of fragmented vs. universal regimes: What can we learn from model studies? International Environmental Agreements: Politics, Law and Economics, 9(1), 39-62.

Höhne, N., Blum, H., Matthews, B., Fuglestvedt, J., Skeie, R. B., Kurosawa, A., et al. (2011). Contributions of individual countries' emissions to climate change and their uncertainty. Climatic Change, 106(3), 359-391.

Höhne, N., den Elzen, M., \& Escalante, D. (2014). Regional GHG reduction targets based on effort sharing: A comparison of studies. Climate Policy, 14(1), 122-147.

Höhne, N., den Elzen, M. G. J., \& Weiss, M. (2006). Common but differentiated convergence (CDC): A new conceptual approach to long-term climate policy. Climate Policy, 6(2), 181-199.

IEA. (2009). World energy outlook 2009. Paris: International Energy Agency.

IEA. (2012). Energy statistics and balances. Paris: International Energy Agency.

JRC/PBL. (2012). EDGAR version 4.2 FT2010. Joint Research Centre of the European Commission/PBL Netherlands Environmental Assessment Agency. http://edgar.jrc.ec.europa.eu/index.php.

Kindermann, G., Obersteiner, M., Sohngen, B., Sathaye, J., Andrasko, K., Rametsteiner, E., et al. (2008). Global cost estimates of reducing carbon emissions through avoided deforestation. Proceedings of the National Academy of Sciences of the United States of America, 105(30), 10302-10307.

Kriegler, E., Tavoni, M., Aboumahboub, T., Luderer, G., Calvin, K., Maere, G. D., et al. (2013). What does the 2C target imply for a global climate agreement in 2020? The LIMITS study on Durban Platform scenarios. Climate Change Economics, 4(4), 1340008.

Lucas, P., van Vuuren, D. P., Olivier, J. A., \& den Elzen, M. G. J. (2007). Long-term reduction potential of non- $\mathrm{CO}_{2}$ greenhouse gases. Environmental Science \& Policy, 10(2), 85-103.

Meinshausen, M., Jeffery, L., Guetschow, J., Robiou du Pont, Y., Rogelj, J., Schaeffer, M., et al. (2015). National post-2020 greenhouse gas targets and diversity-aware leadership. Nature Climate Change, 5 , 1098-1106.

Meyer, A. (2000). Contraction and convergence: The global solution to climate change (Vol. 5). Bristol: Schumacher Briefings, Green Books.

O’Neill, B. C., Kriegler, E., Riahi, K., Ebi, K. L., Hallegatte, S., Carter, T. R., et al. (2014). A new scenario framework for climate change research: The concept of shared socioeconomic pathways. Climatic Change, 122(3), 387-400.

Pan, J. (2005). Meeting human development goals with low emissions: An alternative to emissions caps for post-Kyoto from a developing country perspective. International Environmental Agreements: Politics, Law and Economics, 5, 89-104.

Pan, X., Teng, F., Ha, Y., \& Wang, G. (2014a). Equitable access to sustainable development: Based on the comparative study of carbon emission rights allocation schemes. Applied Energy, 130, 632-640.

Pan, X., Teng, F., \& Wang, G. (2014b). A comparison of carbon allocation schemes: On the equityefficiency tradeoff. Energy, 74(C), 222-229.

Pan, X., Teng, F., \& Wang, G. (2014c). Sharing emission space at an equitable basis: Allocation scheme based on the equal cumulative emission per capita principle. Applied Energy, 113, 1810-1818.

Peterson, E. B., Schleich, J., \& Duscha, V. (2011). Environmental and economic effects of the Copenhagen pledges and more ambitious emission reduction targets. Energy Policy, 39(6), 3697-3708.

Raupach, M. R., Davis, S. J., Peters, G. P., Andrew, R. M., Canadell, J. G., Ciais, P., et al. (2014). Sharing a quota on cumulative carbon emissions. Nature Climate Change, 4(10), 873-879.

Riahi, K., Kriegler, E., Johnson, N., Bertram, C., den Elzen, M., Eom, J., et al. (2015). Locked into Copenhagen pledges-Implications of short-term emission targets for the cost and feasibility of longterm climate goals. Technological Forecasting and Social Change, 90(PA), 8-23.

Ringius, L., Torvanger, A., \& Holtsmark, B. (1998). Can multi-criteria rules fairly distribute climate burdens? OECD results from three burden sharing rules. Energy Policy, 26(10), 777-793.

Ringius, L., Torvanger, A., \& Underdal, A. (2002). Burden sharing and fairness principles in international climate policy. International Environmental Agreements: Politics, Law and Economics, 2, 1-22. 
Rive, N., Torvanger, A., \& Fuglestvedt, J. S. (2006). Climate agreements based on responsibility for global warming: Periodic updating, policy choices, and regional costs. Global Environmental Change, 16(2), 182-194.

Rogelj, J., Nabel, J., Chen, C., Hare, W., Markmann, K., Meinshausen, M., et al. (2010). Copenhagen accord pledges are paltry. Nature, 464(7292), 1126-1128.

Rose, A., Stevens, B., Edmonds, J., \& Wise, M. (1998). International equity and differentiation in global warming policy: An application to tradeable emission permits. Environmental \& Resource Economics, 12(1), 25-51.

Russ, P., \& Criqui, P. (2007). Post-Kyoto $\mathrm{CO}_{2}$ emission reduction: The soft landing scenario analysed with POLES and other world models. Energy Policy, 35, 786-796.

Russ, P., \& van Ierland, T. (2009). Insights on different participation schemes to meet climate goals. Energy Economics, 31(Suppl. 2), S163-S173.

Schwarz, W., Gschrey, B., Leisewitz, A., Herold, A., \& Gores, S. (2011). Preparatory study for a review of Regulation (EC) No 842/2006 on certain fluorinated greenhouse gases. Final report prepared for the European Commission in the context of service contract no 070307/2009/548866/SER/C4. http://ec. europa.eu/clima/policies/f-gas/docs/2011_study_en.pdf.

Stehfest, E., van Vuuren, D., Kram, T., Bouwman, L., Alkemade, R., Bakkenes, M., et al. (2014). Integrated assessment of global environmental change with IMAGE 3.0. Model description and policy applications. The Hague: PBL Netherlands Environmental Assessment Agency.

Tavoni, M., Kriegler, E., Riahi, K., van Vuuren, D. P., Aboumahboub, T., Bowen, A., et al. (2015). Post2020 climate agreements in the major economies assessed in the light of global models. Nature Climate Change, 5(2), 119-126.

UNEP. (2014). The emissions gap report 2014. Nairobi: United Nations Environment Programme (UNEP).

UNEP. (2015). The emissions gap report 2015. Nairobi: United Nations Environment Programme (UNEP).

UNFCCC. (1995). Climate Change 1995, the science of Climate Change: Summary for policymakers and technical summary of the working group I report.

UNFCCC. (1997). Paper no. 1: Brazil; proposed elements of a protocol to the united nations framework convention on climate change. UNFCCC/AGBM/1997/MISC.1/Add.3 GE.97. Bonn.

UNFCCC. (2010). Report of the conference of the parties on its sixteenth session, held in Cancun from 29 November to 10 December 2010. Addendum. Part Two: Action taken by the Conference of the Parties at its sixteenth session. FCCC/CP/2010/7/Add.1.

UNFCCC. (2012). Quantified economy-wide emission reduction targets by developed country Parties to the Convention: Assumptions, conditions, commonalities and differences in approaches and comparison of the level of emission reduction efforts. UNFCCC document FCCC/TP/2012/2. United Nations Framework Convention on Climate Change.

UNFCCC. (2015). Adoption of the Paris agreement: Proposal by the president. FCCC/CP/2015/L.9/Rev.1.

United Nations. (1992). United Nations Framework Convention on Climate Change. New York, NY. http:// www.unfccc.int.

Van Ruijven, B. J., Van Vuuren, D. P., Van Vliet, J., Beltran, A. M., Deetman, S., \& Den Elzen, M. G. J. (2012a). Implications of greenhouse gas emission mitigation scenarios for the main Asian regions. Energy Economics, 34(SUPPL. 3), S459-S469.

Van Ruijven, B. J., Weitzel, M., den Elzen, M. G. J., Hof, A. F., van Vuuren, D. P., Peterson, S., et al. (2012b). Emission allowances and mitigation costs of China and India resulting from different effortsharing approaches. Energy Policy, 46, 116-134.

van Vliet, J., van den Berg, M., Schaeffer, M., van Vuuren, D. P., den Elzen, M., Hof, A. F., et al. (2012). Copenhagen accord pledges imply higher costs for staying below $2{ }^{\circ} \mathrm{C}$ warming. Climatic Change, 113(2), 551-561.

Wada, K., Sano, F., Akimoto, K., \& Homma, T. (2012). Assessment of Copenhagen pledges with long-term implications. Energy Economics, 34(Suppl. 3), S481-S486. 